\title{
AVALIAÇÃO DAS CARACTERÍSTICAS AGRONÔMICAS DE CULTIVARES DE MAMONA SEMEADA EM LONDRINA, PR
}

\author{
ZORZENONI, Thiago Ometto ${ }^{1}$ \\ OKUMURA, Ricardo Shigueru ${ }^{2}$ \\ MARIANO, Daiane de Cinque ${ }^{2}$ \\ ZACCHEO, Paulo Vicente Contador ${ }^{3}$ \\ PRETE, Cássio Egídio Cavenaghi ${ }^{4}$
}

RESUMO: O objetivo deste trabalho foi avaliar o desempenho de cultivares de mamona na região de Londrina PR. O estudo foi instalado em 14 de outubro de 2005, a campo, na Fazenda Experimental da Universidade Estadual de Londrina. O delineamento experimental utilizado foi o de blocos casualizados com 4 repetições, sendo os tratamentos constituídos pelas 9 cultivares, das quais são 2 híbridos (Savana e Íris), 4 variedades (IAC Guarani, IAC 80, IAC 226 e AL Guarany 2002) e 3 variedades locais (Preta, Coti e Sangue de Boi). Verifica-se que as boas condições ambientais favoreceram o bom desenvolvimento da cultura da mamona, sendo que a porcentagem de emergência à campo das plântulas foi elevada para os híbridos. Com relação às épocas de floração observa-se que os híbridos Savana e Íris foram as mais precoces, seguidos pelas variedades IAC-226 e AL Guarany 2002 e, por fim as variedades IAC-80, Coti e Sangue de Boi as mais tardias. Constata-se que a cultivar IAC Guarani foi a mais produtiva, em contrapartida a menor produtividade foi proporcionada pelas cultivares IAC-80, AL Guarany 2002 e Sangue de Boi.

Palavras-chave: Ricinus communis L. Época de floração. Desenvolvimento vegetativo.

\section{EVALUATION OF AGRONOMIC CHARACTERISTICS OF CULTIVARS OF CASTOR BEAN PLANTED IN LONDRINA, PR.}

\begin{abstract}
SUMMARY: The aim of this study was to evaluate the performance of castor varieties in Londrina - PR. The study was installed on October 14, 2005, the field, at Experimental Farm of the State University of Londrina. The experimental design was a randomized complete block with four replications, treatments consisted of nine cultivars, two of which are hybrids (Savana and Iris), four varieties (IAC Guarani, IAC 80, IAC 226 and AL Guarany 2002) and 3 local varieties (Preta, Coti and Sangue de Boi). It appears that good environmental conditions favored the development of castor bean, and the percentage of field emergence of seedlings was high for hybrids. With respect to blooming is observed that the hybrids Savannah and Iris were earlier, followed by IAC-226 and AL Guarany 2002 and ultimately the varieties IAC-80, Coti and Sangue de Boi later. It appears that the IAC Guarani was the most productive, however the lowest yield was provided by cultivars IAC-80, AL 2002 Guarany and Sangue de Boi.
\end{abstract}

Keywords: Ricinus communis L. Flowering time. Vegetative growth.

\footnotetext{
${ }^{1}$ Engenheiro Agrônomo, Dedini S/A Indústrias de Base.

${ }^{2}$ Doutorando do curso de pós-graduação em Agronomia, Universidade Estadual de Maringá. Bolsista Capes e CNPq, respectivamente. E-mail: ricardo_okumura@hotmail.com

${ }^{3}$ Doutorando do curso de pós-graduação em Agronomia, Universidade Estadual de Londrina. Bolsista Capes.

${ }^{4}$ Professor Associado, Universidade Estadual de Londrina, Departamento de Agronomia.
} 


\section{INTRODUÇÃO}

A mamona é uma planta oleaginosa da família Euphorbiaceae, que tem como principais características a ampla adaptabilidade a diferentes ambientes edafoclimáticos (desde as latitudes $40^{\circ} \mathrm{N}$ a $40^{\circ} \mathrm{S}$ ), alto rendimento de óleo (até $50 \%$ do peso do grão) e alta tolerância ao déficit hídrico (SAVY FILHO, 2005), é uma cultura bem adaptada à região semiárida por ser capaz de produzir satisfatoriamente sob pouca disponibilidade de água, mas também por não possuir uma fase crítica na qual a falta d'água possa causar perda total da produção (BARRETO et al., 2010). No entanto, vale ressaltar que a resistência à seca da mamoneira não significa que sua produção não seja influenciada pela quantidade de água disponível no solo.

Atualmente, no Brasil a cultura da mamona (Ricinus communis L.) tem sido objeto de vários estudos. Isso devido ao Projeto de Lei 3368 e medida provisória 214, decretando que a partir de 2008 deverão ser adicionado $2 \%$ de biodiesel ao diesel de petróleo e 5\% a partir de 2013 (HOLANDA, 2006), existindo a possibilidade da cultura se tornar a principal fonte de matéria prima para suprir esta demanda. Entretanto, a cultura da mamona no Brasil possui um acervo tecnológico bastante reduzido quando comparado às outras culturas, como a soja e o milho, o que compromete a sua produção, observando que na safra de 2006/2007 foi de 728 $\mathrm{kg} \mathrm{ha}^{-1}$ (CONAB, 2008), o qual está bem abaixo dos obtidos nos Estados americanos de Missouri e Illionois, na década de 60 (BALDWIN; COSSAR, 2009).

Por sua vez, pode-se considerar que as baixas médias nacionais são decorrentes do baixo nível tecnológico adotado pelo produtor, pelo uso incorreto de insumos e principalmente pela falta de cultivares melhoradas e adaptadas ao local de cultivo (SAVY FILHO, 2005), não permitindo ao produtor retornos condizentes com o capital ou com o serviço familiar investido (AZEVEDO et al., 1998a). Uma alternativa para o aumento da produtividade consiste na adoção de cultivares mais produtivos e adaptados às condições locais, especialmente por ser uma medida que não implica em um aumento substancial do capital investido (GONÇALVES et al., 1981).

Dessa forma, se faz necessários estudos para avaliar o desempenho de cultivares, tendo como intuito verificar o/os que mais se adaptam as regiões de indicação para o seu cultivo, quanto ao seu comportamento bem como as suas respostas ou reações às características edafoclimáticas da região indicada, assim como aos inimigos naturais (insetos pragas e patógenos). Fornecendo dados que possibilitam indicar cultivares de maior valor econômico, de acordo com sistema de plantio característico de cada região. Segundo Amaral (2003), para garantir retornos econômicos competitivos em relação às outras culturas, torna-se necessário o 
uso de tecnologias e o desenvolvimento de cultivares com características agronômicas desejáveis.

O objetivo do presente trabalho foi avaliar o desempenho de cultivares de mamona na região de Londrina - PR, identificando as mais promissoras e adaptadas às condições da região.

\section{MATERIAL E MÉTODOS}

O experimento foi instalado e conduzido a campo, na safra 2005/2006, na Fazenda Escola da Universidade Estadual de Londrina, Londrina/PR, cujas coordenadas geográficas são: altitude $549 \mathrm{~m}$, latitude $23^{\circ} 20^{\prime} \mathrm{S}$ e longitude $51^{\circ} 12^{\prime} \mathrm{W}$. O clima da região é do tipo Cfa, segundo a classificação de Köppen. O solo é classificado como Latossolo Vermelho eutroférrico (EMBRAPA, 1999), cujas características químicas, na instalação do experimento são apresentadas na Tabela 1.

Tabela 1. Resultado da análise química de solo da área experimental nas camadas de 0-10 e 10-20 cm, antes da implantação do experimento, no município de Londrina/PR, 2005.

\begin{tabular}{|c|c|c|c|c|c|c|c|c|c|}
\hline Prof. & $\mathrm{pH}^{*}$ & $\mathrm{Ca}^{+2}$ & $\mathrm{Mg}^{+2}$ & $\mathrm{~K}^{+}$ & $\mathrm{Al}^{+3}$ & CTC & MOS** & $\mathrm{V}$ & $\mathrm{P} * * *$ \\
\hline $\mathrm{cm}$ & & ------- & - & $\mathrm{cmol}_{\mathrm{c}}$ & 3 & --------- & $\mathrm{g} \mathrm{kg}^{-1}$ & $\%$ & $\mathrm{mg} \mathrm{dm}^{-3}$ \\
\hline $0-10$ & 4,5 & 3,05 & 1,19 & 0,59 & 0,31 & 12,56 & 3,13 & 38,39 & 8,2 \\
\hline $10-20$ & 4,6 & 3,65 & 1,39 & 0,75 & 0,15 & 12,47 & 3,46 & 46,43 & 11,3 \\
\hline
\end{tabular}

Os dados de precipitação pluviométrica, temperaturas máximas e mínimas ocorridos durante a condução do experimento encontram-se na Figura 1.

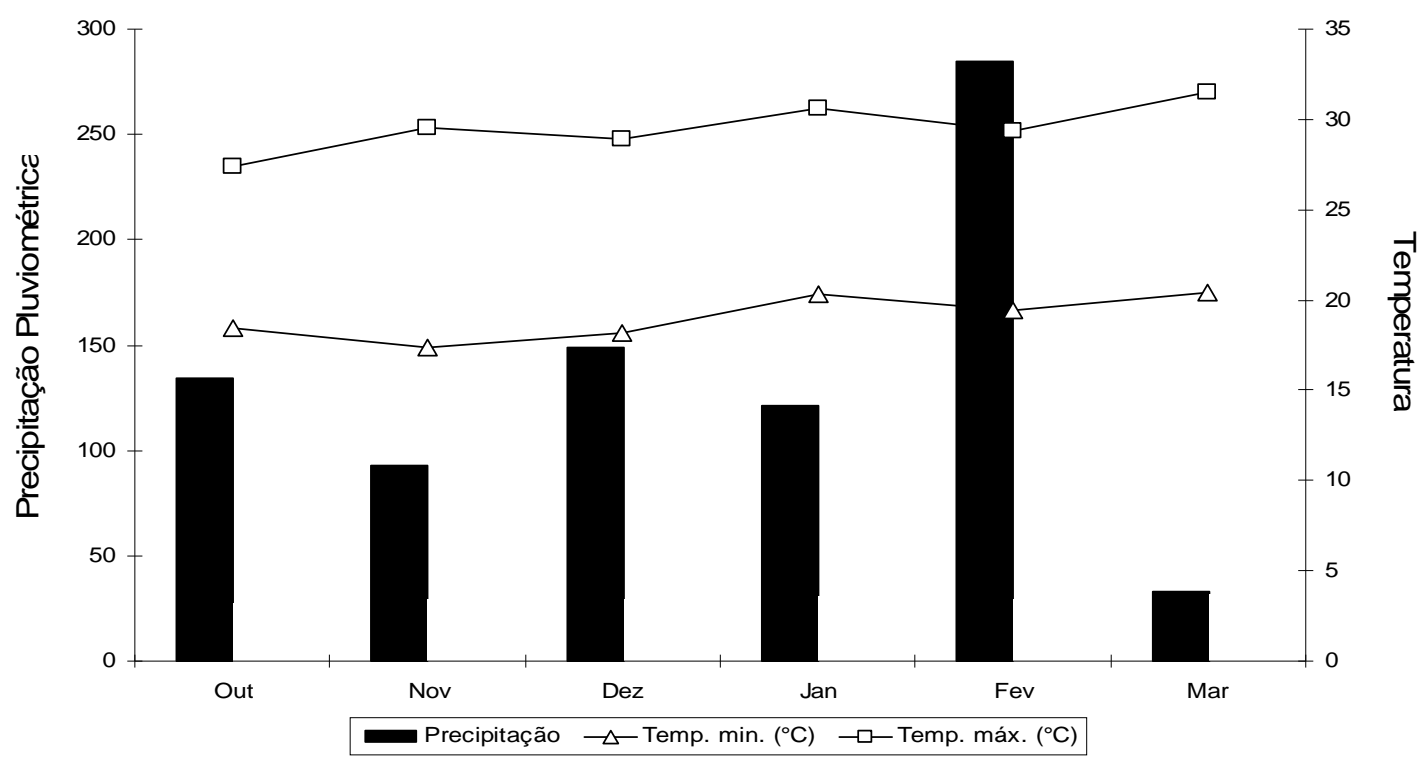

Figura 1. Precipitação pluviométrica $(\mathrm{mm})$ e as temperaturas $\left({ }^{\circ} \mathrm{C}\right)$ máximas e mínimas, nos períodos de outubro a março em Londrina (PR), no ano agrícola de 2005/2006. 
A semeadura foi realizada manualmente em 14 de outubro de 2005, ocorrendo à emergência das plântulas após 12 dias. O espaçamento utilizado foi de 1,0 m entre linhas e 1,0 entre plantas, totalizando 10.000 plantas $\mathrm{ha}^{-1}$, adubada na cova com $100 \mathrm{~kg} \mathrm{ha}^{-1}$ da fórmula 1030-10 e, 40 kg de $\mathrm{N}$ aplicado em cobertura aos 30 dias após a emergência (DAE). O controle das plantas daninhas foi realizado com duas capinas, a primeira executada aos 16 DAE e a segunda aos 46 DAE, não havendo a necessidade do controle de pragas e doenças.

As parcelas constituíram-se de 6 linhas de 1,0 m de espaçamento e 8,0 $\mathrm{m}$ de comprimento, considerando como área útil as 4 linhas centrais, desprezando 1,0 m em cada extremidade. O delineamento experimental utilizado foi o de blocos casualizados com 4 repetições, sendo os tratamentos constituídos pelas cultivares utilizadas, as quais foram 2 hibridos (Savana e Íris), 4 variedades (IAC Guarani, IAC-80, IAC-226 e AL Guarany 2002) e 3 variedades locais (Preta, Coti e Sangue de Boi).

As variáveis consideradas para o estudo foram porcentagem da taxa de emergência da plântula, número de dias até a floração do primeiro, segundo e terceiro cacho (considerada quando $50 \%$ das plantas da parcela estavam florescidas), número de cachos por planta e produtividade por hectare (a colheita foi realizada manualmente na data de 10 de março de 2006).

Os dados obtidos foram submetidos à análise de variância a 5\% de probabilidade pelo teste F, e as médias comparadas pelo teste Duncan a 5\% de probabilidade.

\section{RESULTADOS E DISCUSSÃO}

As boas condições climáticas de pluviosidade e temperatura favoreceram a germinação das sementes, verificando na Figura 2 que a porcentagem de emergência à campo das plantas híbridas Savana e Íris foram de 95,83 e 75,03, respectivamente.

Com relação às variedades IAC Guarani, IAC-226, IAC-80, AL Guarany 2002 e a local Preta, estas apresentaram valores de porcentagem de emergência à campo de 79,29, $94,79,60,42,77,29$ e 75,25, respectivamente. Verificando que a porcentagem de emergência da planta híbrida Savana foi igual estatisticamente a variedade IAC-226.

As cultivares que apresentaram baixa porcentagem de emergência à campo foram as variedades locais Coti e Sangue de Boi, com valores de 38,25 e 45,01, respectivamente. Comparando esses valores com o obtido pela cultivar Savana, observamos uma superioridade do híbrido sobre as variedades locais, isso em decorrência das características de sementes híbridas que proporcionam uma maior uniformidade na emergência das plântulas. 
Verificamos também na Figura 2 que apenas o híbrido Savana e a variedade IAC-226 apresentaram germinação superior ao padrão estabelecido como mínimo para a comercialização dessas sementes no país, que é de $80 \%$ de germinação (DOU, 2007). De acordo com Azevedo e Lima (2001) e Freire, Lima e Andrade (2001), isso ocorre devido o uso de sementes de baixa qualidade, multiplicadas pelos próprios agricultores, acarretando alto grau de heterogeneidade e grande diversidade de tipos locais.

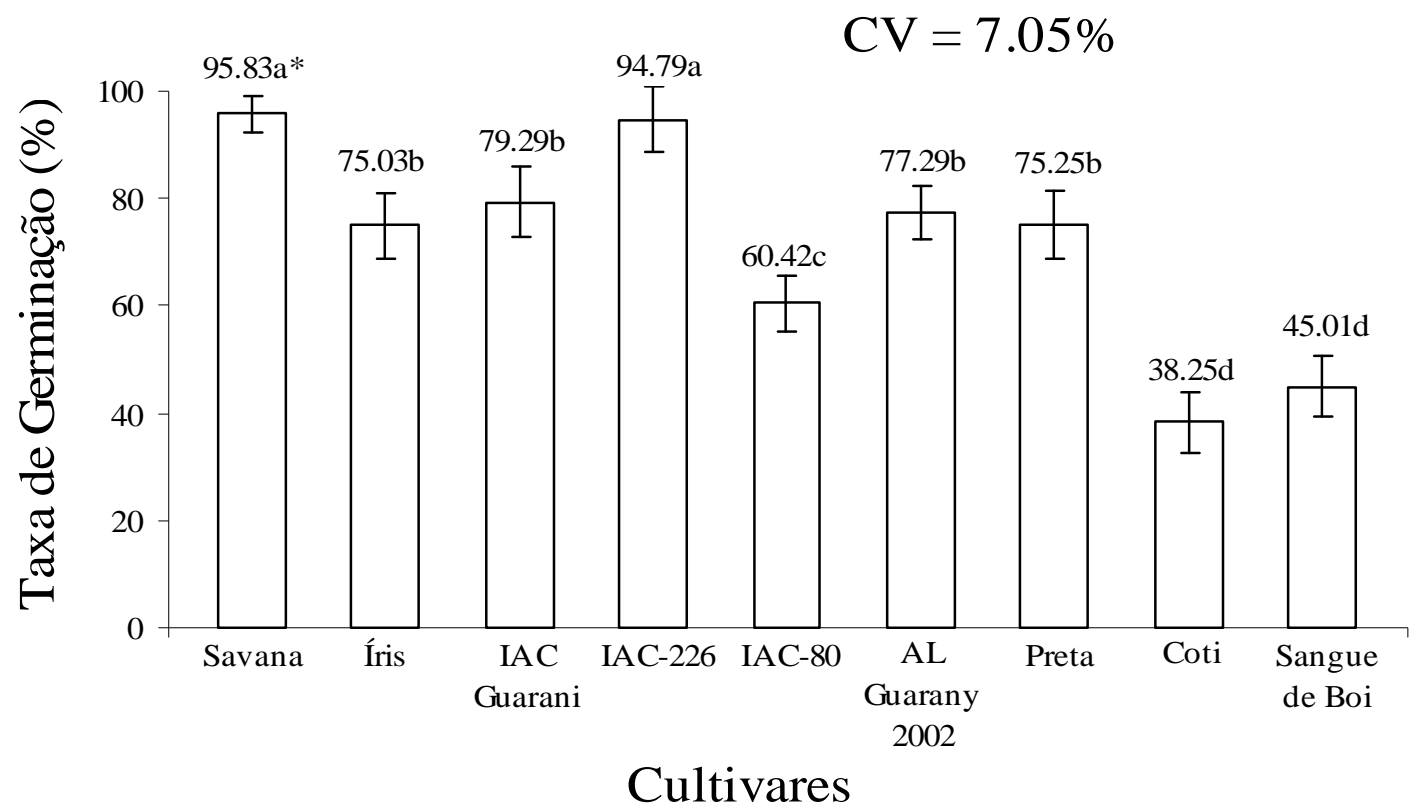

Figura 2. Gráfico de barras apresentando os valores médios da taxa de germinação de plântulas de mamona, no município de Londrina, PR.

*Médias seguidas de mesma letra não diferem estatisticamente pelo teste de Duncan a 5\%.

Na Figura 3, constata-se que na primeira floração $\left(1^{\circ} \mathrm{FL}\right)$ as cultivares IAC Guarani, IAC-226, AL Guarany 2002 e Preta, embora sejam variedades manteve-se no grupo de cultivares precoces, composto pelos híbridos Savana e Íris, ou seja, na $1^{\circ} \mathrm{FL}$ as variedades apresentaram período igual estatisticamente aos híbridos, constatando valores de 63, 63, 69, 69, 72 e 74 DAE para as cultivares Savana, Íris, IAC Guarani, IAC-226, AL Guarany 2002 e Preta, respectivamente.

Observando na Figura 3, que as cultivares mais tardias foram as variedades IAC-80 e as locais Coti e Sangue de Boi, apresentando valores de 80, 80 e 81 DAE, respectivamente, esses valores foram muito acima dos obtidos pelos híbridos Savana e Íris. 


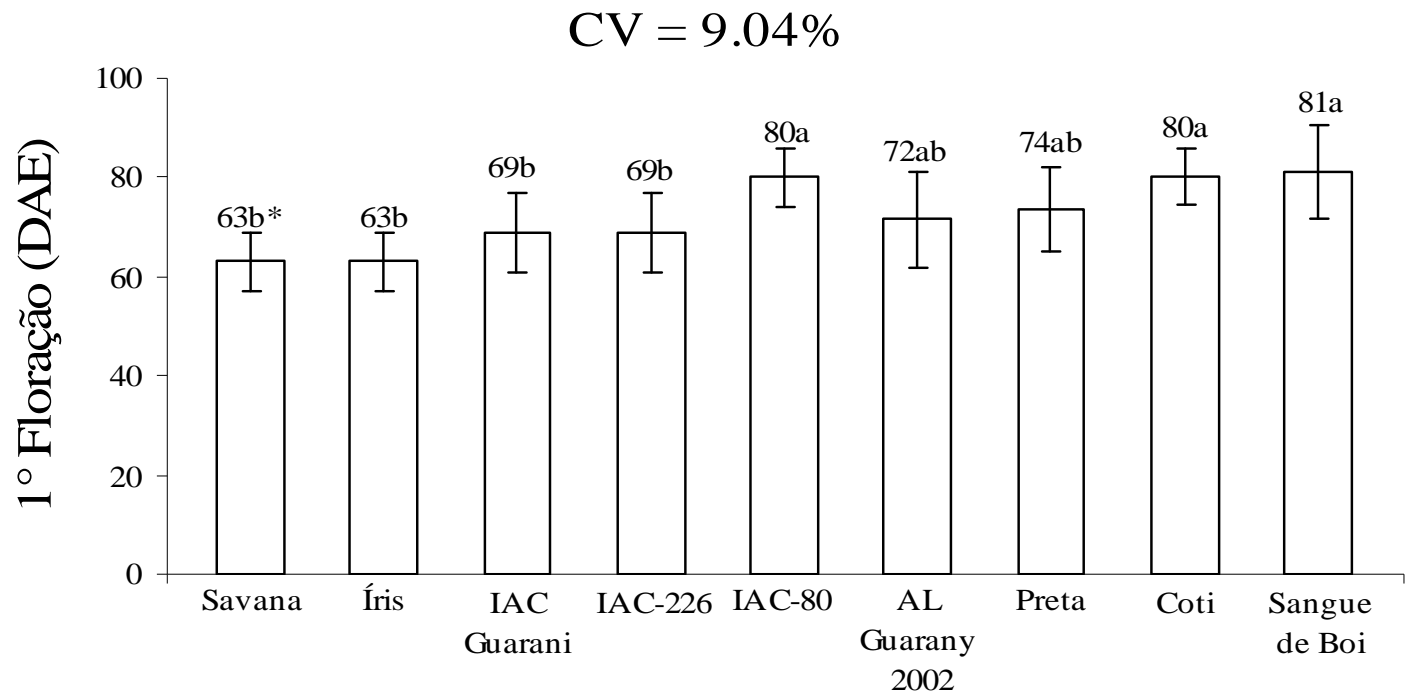

\section{Cultivares}

Figura 3. Gráfico de barras apresentando os valores médios da taxa primeira época de floração da mamona, no município de Londrina, PR.

*Médias seguidas de mesma letra não diferem estatisticamente pelo teste de Duncan a 5\%.

Com relação a segunda floração $\left(2^{\circ} \mathrm{FL}\right)$, pode-se constatar na Figura 4 que novamente há uma precocidade dos híbridos Savana e Íris, a qual apresentou um período de 76 e 73 DAE, respectivamente.

Para as variedades IAC Guarani, IAC-226 e AL Guarany 2002 apresentaram ciclo iguais estatisticamente, observando um período de 87, 84 e 83 DAE (Figura 4), respectivamente. Já a variedade IAC-80 e as locais Coti e Sangue de Boi, apresentaram as três cultivares um período de 103 DAE, ou seja, sendo as mais tardias.

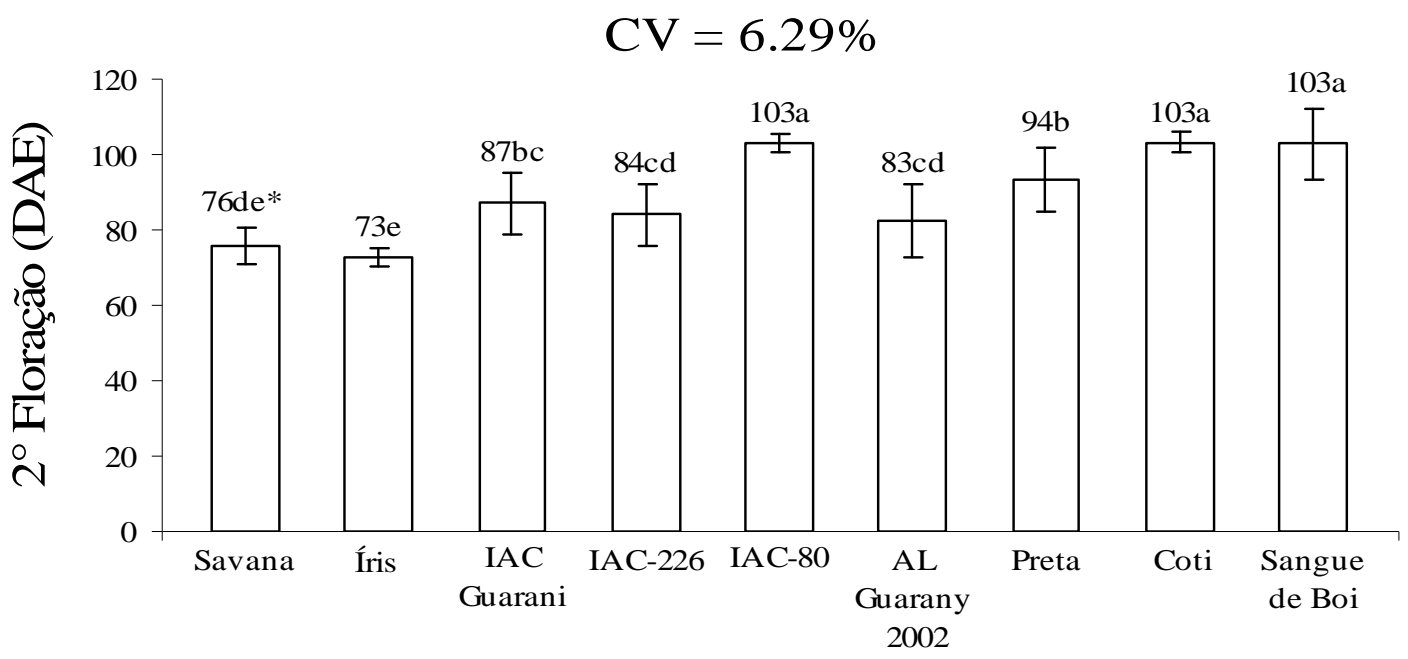

Cultivares

Figura 4. Gráfico de barras apresentando os valores médios da taxa segunda época de floração da mamona, no município de Londrina, PR.

*Médias seguidas de mesma letra não diferem estatisticamente pelo teste de Duncan a 5\%.

$\mathrm{Na}$ terceira época de floração $\left(3^{\circ} \mathrm{FL}\right)$, observa-se pela Figura 5 que existe a mesma 
tendência das outras duas épocas de floração anteriormente, isto é, uma precocidade dos híbridos, sendo que estas obtiveram valores de 93 e 87 DAE para os híbridos Savana e Íris, respectivamente. Inferindo que nas condições de Londrina-PR, verifica-se que nesse estudo os híbridos necessitaram de menor período de dias para completar o seu ciclo de desenvolvimento.

As cultivares com número de dias intermediários para alcançar o estádio da $3^{\circ} \mathrm{FL}$ foram as variedades IAC-226 e AL Guarany 2002, com 108 e 101 DAE, respectivamente. Comparando os valores médios obtidos pelas cultivares IAC-226 e AL Guarany 2002 com os valores obtidos pelos híbridos Savana e Íris, verificamos uma diferença no número de dias de 15 DAE. Esse resultado é similar ao obtido por Aires et al. (2007) que constataram um período vegetativo menor dos híbridos do que as variedades, com diferença no período da $3^{\circ}$ FL de 34 dias.

Com relação às cultivares mais tardias, observamos que a variedade IAC-80 e as locais Coti e Sangue de Boi, foram as que apresentaram maiores números de dias para a $3^{\circ}$ floração, sendo de 134, 133 e 131 DAE, respectivamente. Havendo uma maior preocupação com essas cultivares, em decorrência de um ciclo mais tardio de maturação, ficando mais sujeita as intempéries do ambiente, incidência de patógenos e ataques de pragas.

Analisando as Figura 3, 4 e 5, observarmos que a variedade IAC-226 apresentou as três épocas de floração igual estatisticamente com o AL Guarany 2002, resultados semelhantes foram obtidos por Zuchi et al. (2010), que também não constataram diferença estatística no número de dias para a $1^{\circ}, 2^{\circ}$ e $3^{\circ}$ floração da mamona para essas duas variedades.

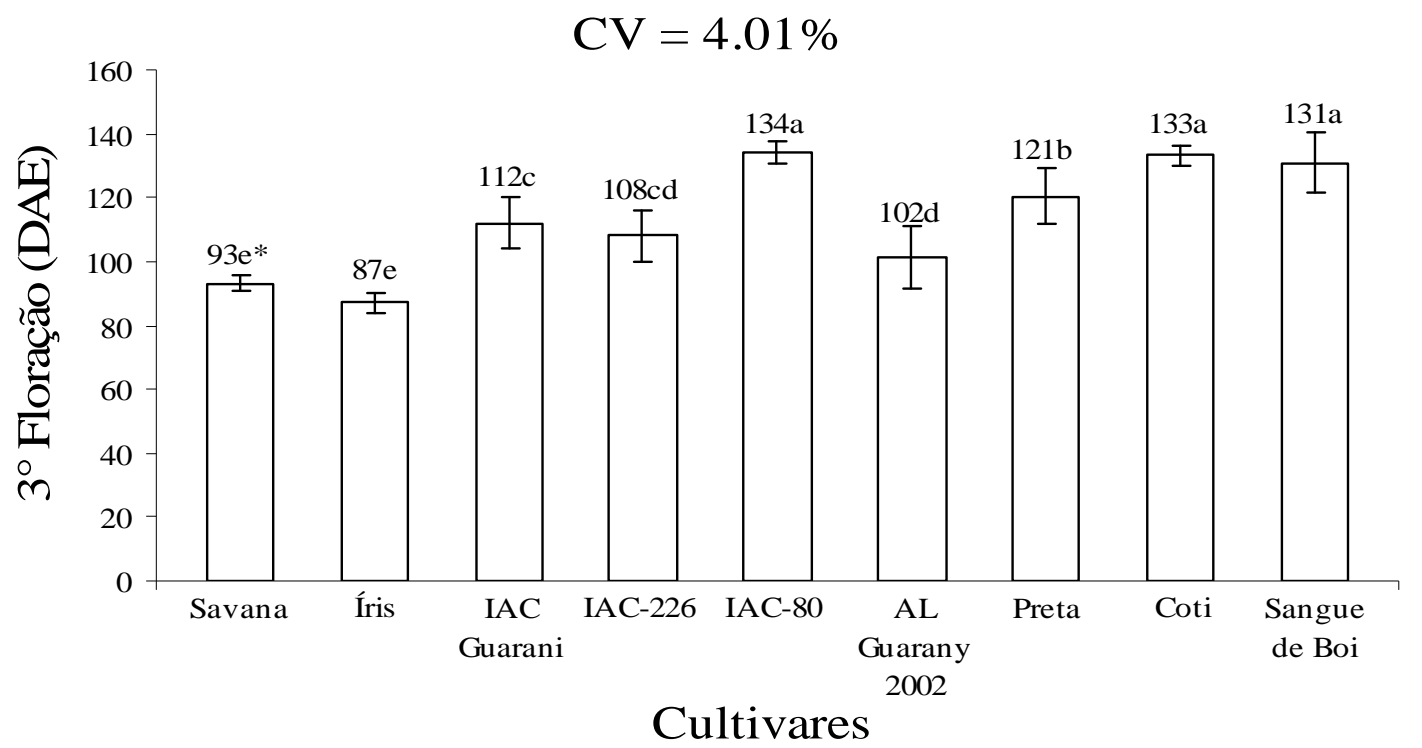

Figura 5. Gráfico de barras apresentando os valores médios da taxa terceira época de floração da mamona, no município de Londrina, PR.

*Médias seguidas de mesma letra não diferem estatisticamente pelo teste de Duncan a 5\%. 
Pelos dados apresentados na Figura 6, constatamos que os híbridos obtiveram o maior número de cachos por planta, sendo que o híbrido Íris foi superior ao Savana, apresentando número de cachos por planta de 4,64 para o Íris e de 3,13 para o Savana.

As cultivares IAC Guarani, AL Guarany 2002 e Preta, apresentaram número de cachos por planta de 2,20, 1,79 e 2,23. Observando na Figura 6, que os valores mais baixos encontrados no presente estudo foi obtido pelas cultivares IAC-226, IAC-80, Coti e Sangue de Boi, apresentando 1,31, 1,18, 1,59 e 1,49 cachos por planta, respectivamente.

Inferindo que os híbridos apresentaram maior número de cachos que as variedades e as cultivares locais, no entanto, esse maior número de cachos não se refletiu em maiores produtividades. Isso ocorre devido à variável número de cachos por planta ser uma característica genética da planta (SILVA et al, 2007).

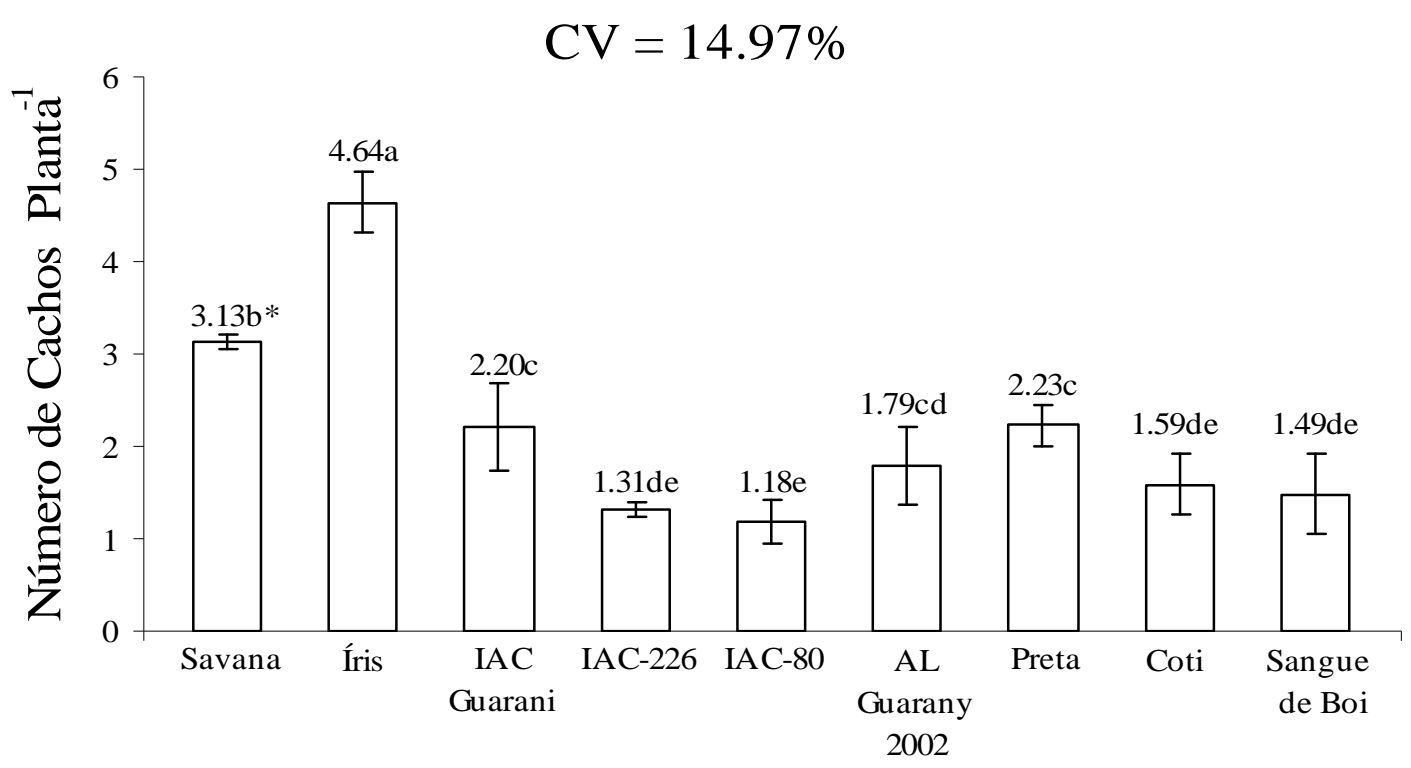

Cultivares

Figura 6. Gráfico de barras apresentando os valores médios do número de cachos por planta de mamona, no município de Londrina, PR.

*Médias seguidas de mesma letra não diferem estatisticamente pelo teste de Duncan a 5\%.

Analisando a Figura 7, observamos que a cultivar mais produtiva foi a variedade IAC Guarani com produtividade de $911 \mathrm{~kg} \mathrm{ha}^{-1}$, seguidos pelas cultivares Savana, Íris, IAC-226, Preta e Coti que apresentaram produtividades iguais estatisticamente de 605, 647, 571, 620 e $547 \mathrm{~kg} \mathrm{ha}^{-1}$, respectivamente. A menor produtividade foi obtida pelas variedades IAC-80, AL Guarany 2002 e Sangue de Boi com valores de 444, 507 e $459 \mathrm{~kg} \mathrm{ha}^{-1}$, respectivamente.

Verifica-se que a produtividade de bagas de mamona foram diferentes estatisticamente, observando variações de 444 a $911 \mathrm{~kg} \mathrm{ha}^{-1}$, para as cultivares IAC-80 e IAC Guarani, respectivamente. Esses resultados são contrários aos obtidos por Corrêa, Távora e 
Pitombeira (2006) que não verificaram diferença estatística entre as estas cultivares estudadas para a variável rendimento de sementes de mamona.

Pelos dados apresentados no presente estudo podemos inferir que a variedade IAC Guarani, nas condições Norte do Paraná, foi a que apresentou o maior potencial produtivo que as demais cultivares citadas. Apesar do IAC Guarani ter sido o mais produtivo, o seu valor está muito abaixo do encontrado por Savy Filho (2005) e Gonçalves et al. (1981) que obtiveram produtividades de 1.500 e $2.011 \mathrm{~kg} \mathrm{ha}^{-1}$, respectivamente.

Com relação ao desempenho de bagas dos híbridos constatamos uma produtividade de $605 \mathrm{~kg} \mathrm{ha}^{-1}$ para a Savana e de $647 \mathrm{~kg} \mathrm{ha}^{-1}$ para a Íris, essa faixa está muito abaixo da obtida por Gonçalves et al. (2005) que relataram em seu estudo, produtividades de 1.370 e $1.021 \mathrm{~kg}$ ha $^{-1}$, respectivamente.

A baixa produtividade constatada no presente estudo pode ser decorrente da elevada densidade populacional, pois segundo Azevedo, Beltrão e Severino (2007), quando a densidade de plantas aumenta por unidade de área, atinge-se um ponto no qual as plantas competem por fatores essenciais de crescimento, como nutrientes, luz e água, proporcionando um efeito negativo na produtividade da cultura. Beltrão et al. (2003) recomenda para cultivar de porte médio os espaçamentos de: 2,0 m x 1,0 m; 3,0 x 1,0 m e 4,0 m x 1,0 m, ou seja, $5.000,3.333$ e 2.500 plantas $\mathrm{ha}^{-1}$, valores esse muito abaixo do utilizado no estudo. Em pesquisa desenvolvida por Azevedo et al. (1998a, b) estudando a influência de diferentes populações de plantas sob o rendimento da mamoneira, verificaram que a máxima

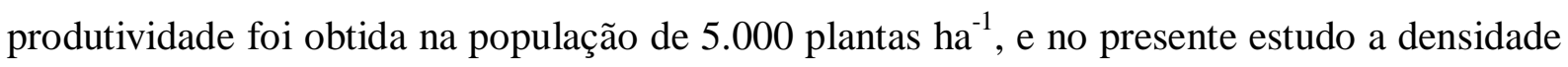
populacional utilizado foi de 10.000 plantas $^{-1}{ }^{-1}$.

A este respeito, Gonçalves, Bendezú e Leles (1981) reportam que existe principalmente em relação a novas cultivares de ciclo precoce escassez de informações sobre espaçamentos e densidade populacional adequados para a cultura, e que grande parte das recomendações ainda são feitas de forma empírica, o que torna de suma importância a realização de pesquisas com este tema. Sabendo que a população de plantas adequada é uma das tecnologias de maior simplicidade de aplicação e que pode resultar em significativo aumento de produtividade (SEVERINO et al., 2006). De acordo com Azevedo, Beltrão e Severino (2007), o espaçamento e a densidade de plantio, bem como a poda Contudo há carência de informações sobre estas práticas culturais, referente a esta oleaginosa.

Vale ressaltar que a produtividade de grãos é o componente de produção que se deve dar especial atenção no manejo da mamoneira, pois o rendimento de óleo é afetado pela produtividade de grãos, e menos pelo conteúdo de óleo presente na semente, que apresenta baixa variação (KOUTROUBAS; PAPAKOSTA; DOITSINIS, 2000). 


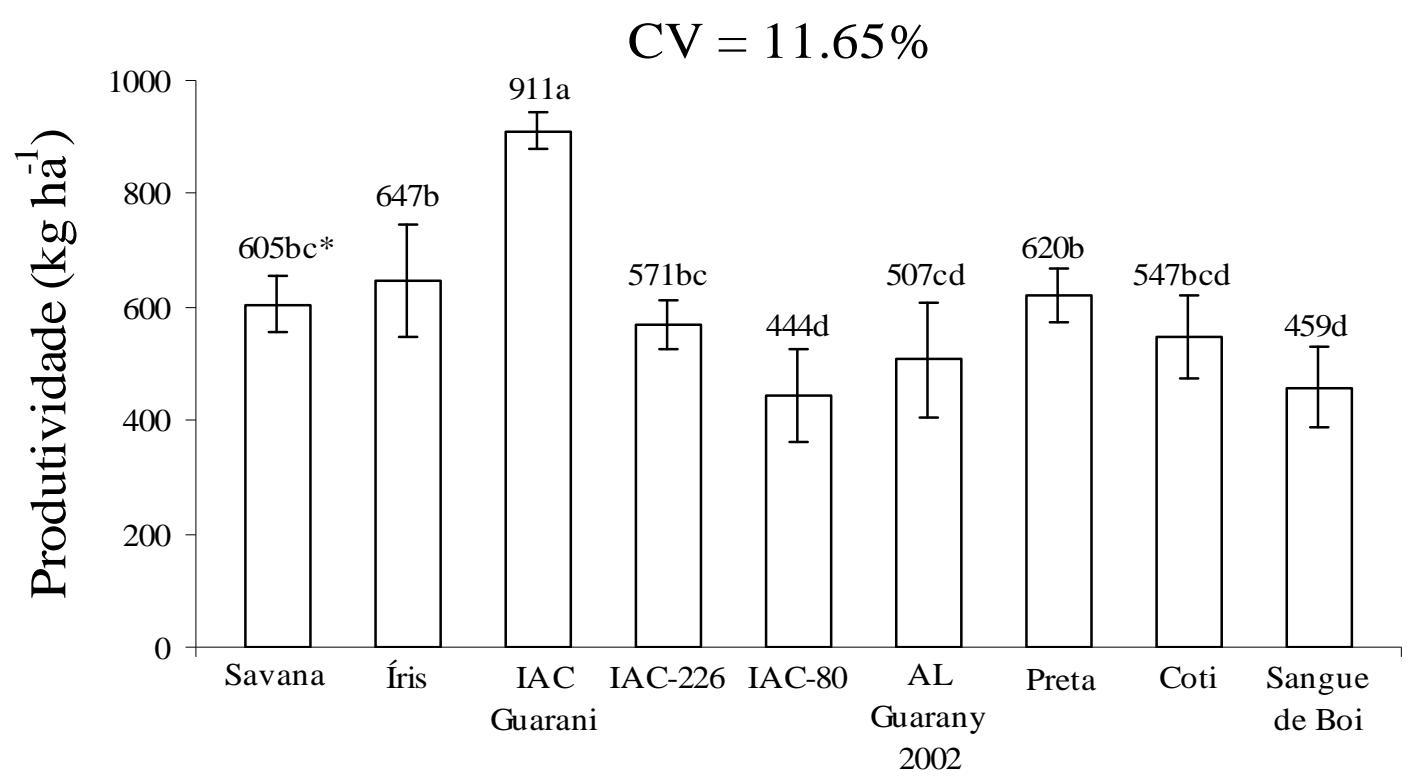

Cultivares

Figura 7. Gráfico de barras apresentando os valores médios da produtividade da mamona, no município de Londrina, PR.

*Médias seguidas de mesma letra não diferem estatisticamente pelo teste de Duncan a 5\%.

Diante das informações do presente estudo, podemos inferir que as produtividades obtidas em outras localidades apresentam-se maiores que as obtidas no experimento, revelando a possibilidade de maiores rendimentos. Esse fato é confirmado pelo alto potencial produtivo das cultivares de mamonas modernas (SAVY FILHO, 2005).

\section{CONCLUSÃO}

As cultivares de mamona mais precoce para o florescimento são os híbridos Íris e Savana com 87 e 93 dias após emergência para completar a $3^{\circ}$ época de floração. Os materiais mais tardios são os IAC 80, Sangue de Boi e Coti, com período para alcançar a $3^{\circ}$ época de floração de 134, 133 e 131 dias após a emergência da mamona.

A variedade IAC Guarani teve boas características de germinação, ciclo fenológio e número de cachos por planta intermediário e elevada produtividade em relação as demais cultivares pesquisada. Sugerindo que para as condições edafoclimáticas da região de Londrina, PR, semeie a cultivar de mamona IAC Guarani. 


\section{REFERÊNCIAS}

AIRES, R.F.; SILVA, S.D.A.E.; CASAGRANDE JR, J.G.; UENO, B.; OLIVEIRA, A.C.B. Desempenho agronômico de cultivares de mamona em Pelotas-RS, 2006/2007. In: Simpósio Estadual de Agroenergia e $1^{\circ}$ Reunião Técnica Anual de Agroenergia-RS, 2007, Pelotas.

Resumos.... Pelotas : Embrapa Clima Temperado, 2007.

AMARAL, J.G.C. do. Variabilidade genética para características agronômicas entre progênies autofecundadas de mamona (Ricinus communis L.) cv. AL Guarani 2002. 2003. 59p. Tese (Doutorado em Agronomia/Agricultura) - Faculdade de Ciências Agronômicas, Universidade Estadual Paulista, Botucatu, 2003.

AZEVEDO, D.M.P. de; BELTRAO, N.E. de M.; SANTOS, J.W. dos; VIEIRA, D.J.; LIMA, E.F.; BATISTA, F.A.S.; PEREIRA, J.R. Efeito de população de plantas no rendimento do consórcio de mamoneira com culturas alimentares. Revista brasileira de oleaginosas fibrosas, v. 2, n. 3, p. 193-202, 1998a.

AZEVEDO, D.M.P. de; BELTRÃO, N.E. de M.; SANTOS, J.W. dos; LIMA, E.F.; BATISTA, F.A.N.; NÓBREGA, L.B. da; VIEIRA, D.J.; PEREIRA, J.R. Efeito de população de plantas no consórcio mamoneira/sorgo. Revista Brasileira de Oleaginosas e Fibrosas, v. 2, n. 3, p. 183-192, 1998 b.

AZEVEDO, D.M.P de; LIMA, E.F. O agronegócio da mamona no Brasil. Embrapa Algodão (Campina Grande, PB). Brasília: Embrapa Informação Tecnológica, 2001. 350p.

AZEVEDO, D.M.P. de; BELTRÃO, N.E. de M.; SEVERINO, L.S. Manejo cultural. In: AZEVEDO, D.M.P. de; BELTRÃO, N.E. de M. O agronegócio da mamona no Brasil. 2 ed. Brasília: Embrapa Informação Tecnológica, 2007. p. 223-253.

BALDWIN, B.S.; COSSAR, R.D. Castor yield in response to planting date at four locations in the south-central United States. Industrial Crops and Products, v. 29, n. 2/3, p. 316-319, 2009.

BARRETO, H.B.F.; MEDEIROS, J.F.; OLIVEIRA, R.A.N.; OLIVEIRA, K.A.; MAIA, P.M.E. Crescimento de acessos de mamona sob condições de irrigação em Mossoró-RN. Revista Verde, v. 5, n. 2, p. 123-130, 2010.

BELTRÃO, N.E.M.; MELO, F.B.; CARDOSO, G.D.; SEVERINO, L.S. Mamona: árvore do conhecimento e sistemas de produção para o semi-árido brasileiro. EMBRAPA: Campina Grande, PB, 2003. 19 p. (Circular Técnica, 70).

COMPANHIA NACIONAL DE ABASTECIMENTO - CONAB. Informação Agropecuária <http://www.conab.gov.br/conabweb/index.php?pag=1011>. Disponível em 01 de novembro de 2008.

CORRÊA, M.L.P.; TÁVVORA, F.J.A.F.; PITOMBEIRA, J.B. Comportamento de cultivares de mamona em sistemas de cultivo isolados e consorciados com caupi e sorgo granífero. Revista Ciência Agronômica, v. 37, n. 2, p. 200-207, 2006. 
DOU - Diário Oficial da União. Ministério da Agricultura, Pecuária e Abastecimento.

Normas para produção e comercialização de sementes de mamona.

<http://www.agricultura.gov.br/pls/portal/docs/PAGE/MAPA/PUBLICÇÕES_DOU/PUBLIC AÇÔES_DOU2005>. Disponível em: 08 de outubro de 2007.

EMBRAPA. Sistema brasileiro de classificação de solos. EMBRAPA/CNPSO. 1999. 412p.

FREIRE, E.C.; LIMA, E.F.; ANDRADE, F.P. Melhoramento Genético. In: AZEVEDO, D.M.P. de; LIMA, E.F. (Ed.). O agronegócio da mamona no Brasil. Brasília: Embrapa Informação Tecnológica, 2001. p. 229-256.

GONÇALVES, N.P.; KAKIDA, J.; BENDEZÚ, J. M.; LELES, W. D. Cultivares de mamona. Informe Agropecuário, v. 7, n. 82, p. 31-33, 1981.

GONÇALVES, N.P.; BENDEZÚ, J.M.; LELES, W.D. Época, espaçamento e densidade de plantio para a cultura da mamona. Informe Agropecuário, v. 7, n. 82, p. 33-35, 1981.

GONÇALVES, N.P.; FARIA, M.A.V.R.; SATURNINO, H.M.; PACHECO, D.D. Cultura da mamoneira. Informe Agropecuário, v. 26, n. 229, p. 28-32, 2005.

HOLANDA, A. Biodiesel: combustível para a cidadania. Brasília: Plenarium, 2006. 30p. (Série Ação Parlamentar, 326).

KOUTROUBAS, S.D.; PAPAKOSTA, D.K.; DOITSINIS, A. Water requirements for castor oil crops (Ricinus communis L.) in a Medierrnean climate. European Journal of Agronomy, p. 3341, 2000.

SAVY FILHO, A. Mamona tecnologia agrícola. Campinas: EMOPI, 2005. 105p.

SEVERINO, L.S.; COELHO, D.K.; MORAES, C.R.A; GONDIM, T.M.S.; VALE, L.S. do. Otimização do espaçamento de plantio para a mamoneira cultivar BRS Nordestina. Revista de Oleaginosas e Fibrosas, v. 10, n. 1/2, p. 993-999, 2006.

SILVA, T.R.B.; LEITE, V.E.; SILVA, A.R.B.; VIANA, L.H. Adubação nitrogenada em cobertura na cultura da mamona em plantio direto. Pesquisa Agropecuária Brasileira, v. 42, n. 9, p. 1357-1359, 2007.

ZUCHI, J.; BEVILAQUA, G.A.P.; ZANUNCIO, J.C.; PESKE, S.T.; SILVA, S.D.A.; SEDIYAMA, C.S. Características agronômicas de cultivares de mamona em função do local de cultivo e da época de semeadura no Rio Grande do Sul. Ciência Rural, v. 40, n. 3, p. 501506, 2010. 